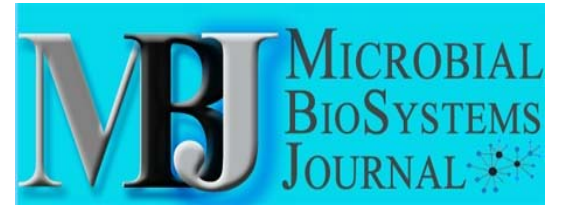

\title{
New record of Chaetomium iranianum MF787598 (Chaetomiaceae) for the Egyptian and African mycobiota
}

\author{
Blanchette RA ${ }^{1 *}$, Held BW ${ }^{1}$ and Abdel-Azeem AM $^{* 2}$ \\ ${ }^{1}$ Department of Plant Pathology, University of Minnesota, St. Paul, MN 55108, US. E-mail: robertb@umn.edu , \\ bheld@umn.edu \\ ${ }^{2}$ Department of Botany, Faculty of Science, Suez Canal University, Ismailia 41522, Egypt- \\ ahmed_abdelazeem@science.suez.edu.eg
}

Blanchette RA, Held BW, Abdel-Azeem AM 2017 - New record of Chaetomium iranianum MF787598 (Chaetomiaceae) for the Egyptian and African mycobiota. Microbial Biosystems 2(2), 6-9.

\begin{abstract}
The first record of Chaetomium iranianum (Ascomycota, Chaetomiaceae) for the Egyptian and African fungi is reported here. The species was found during an extensive taxonomic and ecological revision of genus Chaetomium supported by Science and Development Technology Fund (STDF) in Egypt. Chaetomium iranianum identified phenotypically and was subjected to sequencing for confirmation of phenotypic identification. The internal transcribed spacer (ITS) 1-5.8 s - ITS2 rDNA sequences obtained were compared with those deposited in the GenBank Database and registered with accession number MF787598 in the NCBI Database. We provide an updated full description and illustration of the species.
\end{abstract}

Key words- Endobionts, Saint Katherine Protectorate, Sinai, Teucrium polium, taxonomy.

\section{Introduction}

Chaetomium is a large genus of the ascomycetous family Chaetomiaceae that was established by Gustav Kunze in 1817 based on C. globosum as its type species. Since the establishment of the genus, more than 300 species have been described, many of which were synonymized/excluded. The total number of Chaetomium species so far described is about163 in 2013 by Doveri. By scanning of available sources of information concerning genus Chaetomium in Egypt, it was possible to determine 53 species and one variety isolated/reported from different substrates (Moustafa \& Abdel-Azeem, 2005) without any record of Chaetomium iranianum until now. Here we report Chaetomium iranianum Asgari \& Zare hosted Teucrium polium L. which constitutes the first record of this species in Egypt and Africa.

\section{Materials and methods}

\section{Study area, sampling and isolation of endobiont fungi}

One hundred samples of four plant species namely: Teucrium polium L., Chiliadenus montanus (Vahl) Brullo, Origanum syriacum L. and Verbascum sinaiticum Benth were collected from twenty localities in four wadis namely: Wadi Itlah $\left(28^{\circ} 58^{\prime} 72.3^{\prime \prime} \mathrm{N}, 33^{\circ} 92^{\prime} 01.7^{\prime \prime} \mathrm{E}\right)$, Wadi

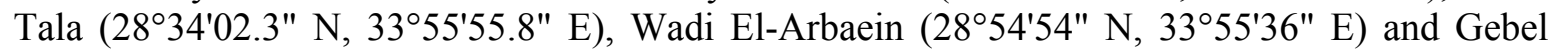

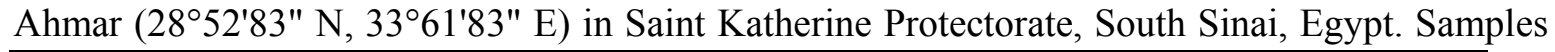
permits unrestricted use, distribution, and reproduction in any medium, provided the original author and source are credited. 
were collected under permission of the Saint Katherine Protectorate for scientific purposes and no endangered species were involved in the study.

A total of 400 plates were used for the isolation of endobiont mycobiota (100 plates/plant). Pieces of stem and leaves $\left(5 \mathrm{~mm}^{2}\right.$, four pieces in each plate) were surface sterilized and cut. The sections were washed three times in running water, immersed in $70 \%$ ethanol for $1-$ $5 \mathrm{~min}$, dipped in $5 \% \mathrm{NaOCl}$ for $3-5 \mathrm{~min}$, according to the plant thickness, and then dipped in $70 \%$ ethanol for $0.5 \mathrm{~min}$ (Abdel-Azeem \& Salem, 2012), before being plated on appropriate isolation media. For primary isolation, Czapek's yeast extract agar, Oat Meal Agar, and Potato Dextrose Agar (PDA) media supplemented with Rose bengal (1/1500), chloramphenicol (50 ppm) were used.

\section{Phenotypic identification}

Identification of recovered Chaetomium isolates was conducted up to the species level based on phenotypic characteristics using the relevant identification keys for Chaetomium (Asgari \& Zare 2011; Doveri 2013). The names of the authors of fungal taxa were abbreviated according to Kirk and Ansell (1992). All name corrections, authorities, and taxonomic assignments of recorded species in the present study were checked against the Index Fungorum database (2017). All isolated taxa are maintained in the Fungarium of Suez Canal University (FSCU) at Arab Society for Fungal Conservation (ASFC) in Botany Department, Faculty of Science, University of Suez Canal, Ismailia, Egypt.

\section{Molecular identification}

DNA was extracted from fungal culture using an adapted chloroform procedure (Arenz \& Blanchette 2011). The internal transcribed spacer (ITS) region of ribosomal DNA was targeted for PCR amplification with the primers ITS1 and ITS4 for large subunit amplification (White et al. 1990). PCR amplifications were done using Amplitaq Gold PCR Master-mix (Applied Biosystems, Foster City, CA) and $1 \mathrm{ml}$ of template DNA using the following parameters: $94{ }^{\circ} \mathrm{C}$ for $5 \mathrm{~min}, 35$ cycles of $94{ }^{\circ} \mathrm{C}$ for $1 \mathrm{~min}, 50{ }^{\circ} \mathrm{C}$ for $1 \mathrm{~min}, 72{ }^{\circ} \mathrm{C}$ for $1 \mathrm{~min}$, and a final extension step of $5 \mathrm{~min}$ at $72{ }^{\circ} \mathrm{C}$. PCR amplicons were visualized on a $1 \%$ agarose gel using SYBR green 1 (Life Technologies, Grand Island, NY) prestain and a Dark Reader DR45 transilluminator (Clare Chemical Research, Denver, CO). Primers used for PCR were used for sequencing reactions on automated DNA sequencer (Model 3100; PerkinEl-merInc/Applied Biosystems - Bioneer, South Korea), according to the manufacturer's protocol. Consensus sequences were assembled using Geneious 9.0 (Kearse et al. 2012) and compared to those in GenBank using BLASTn for identification.

\section{Light and Scanning Electron Microscopy Examination}

Fruit bodies of Chaetomium iranianum was mounted in deionized water according to Abdel-Azeem (1998) to examine their appendages, ascospores and textura by light microscope. For scanning electron microscopy fungus was grown in Petri dishes on the appropriate media to obtain typical and good sporulation. Small pieces of agar $(6-8 \times 5 \mathrm{~mm})$ with the fungus (or, when fresh, parts of the natural substrate) were cut from the colonies, put into stubs using double-sided sticky tape, stubs and fixed in unbuffered aqueous $2 \% \mathrm{OsO}_{4}$ overnight. The samples were then transferred to a critical point drying apparatus (Balzer) and dried in $\mathrm{CO}_{2}$. The specimens were coated with gold in a sputter coater (Polaron) and examined and photographed with a Hitachi S3500 scanning electron microscope

\section{Results}

Five species of Chaetomium were recovered from four medicinal plants during this extensive survey namely: C. bostrychodes Zopf., C. globosum Knuze, C. iranianum Asgari \& Zare, C. 
piluliferum J. Daniels and C. senegalense L.M. Ames. All taxa were previously reported in Egypt except $C$. iranianum.

\section{Taxonomic treatment}

\section{Chaetomium iranianum Asgari \& Zare, Mycologia 103(4): 877 (2011)}

MF787598 (Figure 1 A-E)

Colonies. With a daily growth rate of $7-8 \mathrm{~mm}$ on OMA, flocosse, ivory-white, at the margin pale yellow; reverse pale yellowish brown. Ascomata. Maturing within 15 days, pale gray in reflected light, superficial, spherical, globose to subglobose, ostiolate, 100-150 $\mu \mathrm{m}$ diam; ascomatal wall pale brown, of textura intricata; ascomatal hairs numerous, usually unbranched, straight below, spirally to loosely coiled in the upper part, often tapering, septate, reddish brown, 2.3-3 $\mu \mathrm{m}$ broad at the middle, up to $550 \mu \mathrm{m}$ long, finely verrucose (ornaments lacerate). Asci. Fasciculate, clavate or fusiform, short-stalked, 24-39 $\times 10-12 \mu \mathrm{m}, 8$-spored, evanescent. Ascospores. Biseriately arranged, inequilaterally fusiform or navicular, often irregular 10-11 × 5.5-6.5 $\mu \mathrm{m}$, with a subapical occasionally germ pore. Paraphyses. Not observed. Anamorph absent.

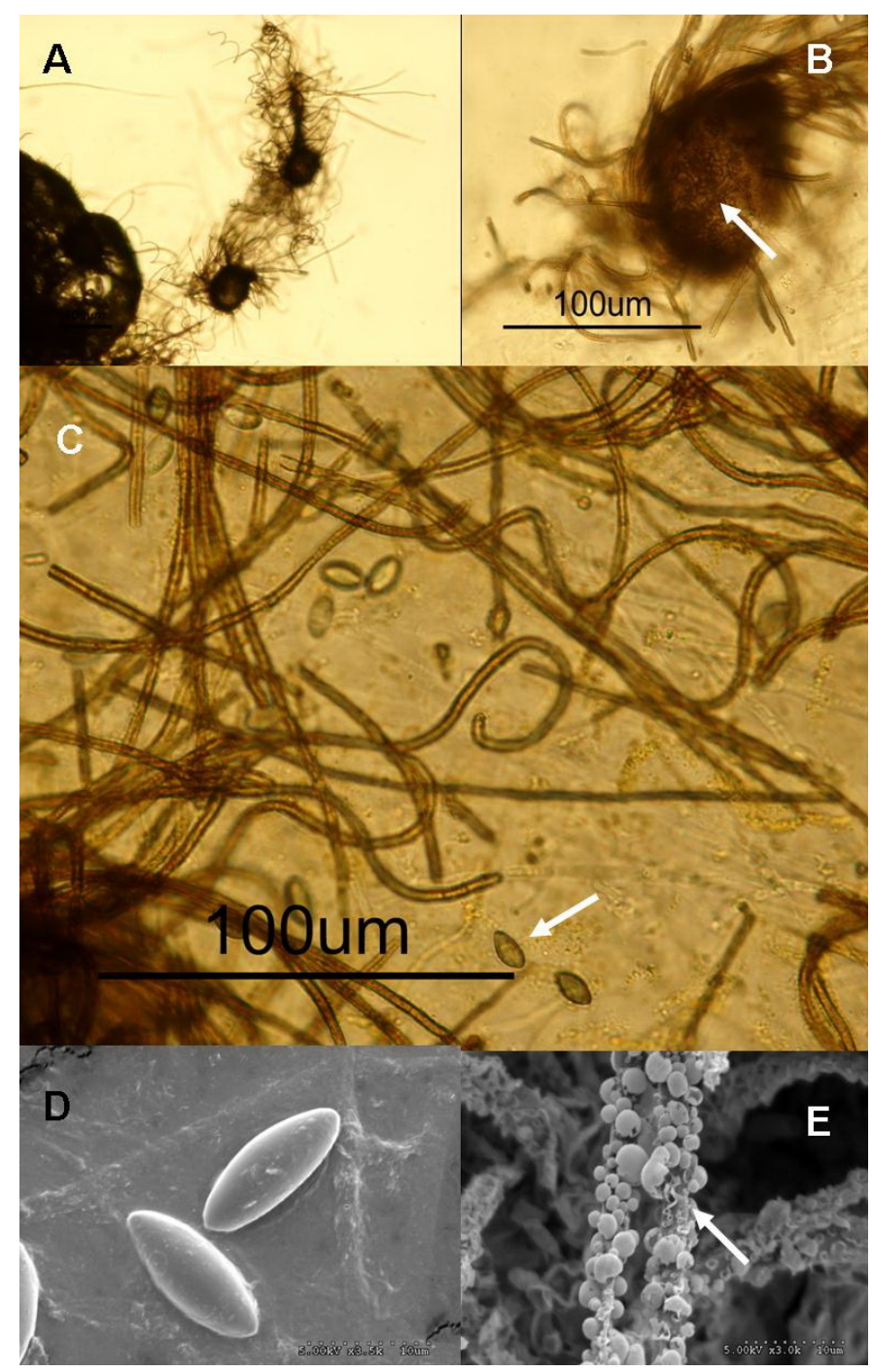


Fig. 1- Chaetomium iranianum. A. Mature ascomata; B. Textura intricata by light microscope; C. Ascomatal hairs and ascospores by light microscope; D. Mature ascospores (SEM); E. Lacerate ornaments (SEM).

Specimens Examined-Egypt, isolated from Teucrium polium, Saint Katherine Protectorate, South Sinai, Egypt, 11 June 2014, 27 August 2015, 30 November 2015, 28 December 2016, leg. Ahmed M. Abdel-Azeem, det. Ahmed .M. Abdel-Azeem (SCUF-144, 161, 219, 275).

\section{Conservation status}

Conservation of fungi in Egypt and worldwide remains very low, and more education on fungal conservation is urgently needed. Although the species distribution is restricted only in South Sinai, Egypt, and in this state, data deficient (DD) is the conservation status of this fungal species according to the IUCN criteria (2010).

\section{Acknowledgements}

This work was supported by the Science and Development Technology Fund in Egypt (STF project No. 12295). The authors would like to thank Ms. Fatma M. Salem for her invaluable support during laboratory work and we would also like to thank the two anonymous reviewers for the valuable suggestions.

\section{Conflict of Interest}

The authors do not have any conflicts of interest.

\section{References}

Abdel-Azeem, A. 1998. Cytogenetical and Biological Studies on the fungus Chaetomiopsis. M.Sc. Thesis, Suez Canal University, Ismailia, Egypt, 240 pp.

Abdel-Azeem, A. M. and Salem, F. M. 2012. Biodiversity of laccase producing fungi in Egypt. Mycosphere 3(5): 900-920.

Arenz, B. and Blanchette, R. 2011. Distribution and abundance of soil fungi in Antarctica at sites on the Peninsula, Ross Sea region and McMurdo dry valleys. Soil Biol. Biochem. 43: 308-315.

Asgari, B. and Zare, R. 2011. The genus Chaetomium in Iran, a phylogenetic study including six new species. Mycologia 103: 863-882.

Doveri, F. 2013. An additional update on the genus Chaetomium with descriptions of two coprophilous species, new to Italy. Mycosphere 4: 820-846.

Kunze, G. And Schmidt, J. K. 1817. Mykologische Hefte. Leipzig, 1(1):16.

Index Fungorum database. Avaliable from http://www.indexfungorum.org/names/Names.asp (accessed: 7 Dec 2017).

IUCN. (2010) Guidelines for Using the IUCN Red List Categories and Criteria. Version 8.1. Available from: <http://intranet.iucn.org/webfiles/doc/SSC/ RedList/RedListGuidelines.pdf $>$ (accessed: 7 Dec 2017).

Kearse, M., Moir, R., Wilson, A., Stones-Havas, S., Cheung, M., Sturrock, S., et al. 2012. Geneious basic: an integrated and extendable desktop software platform for the organization and analysis of sequence data. Bioinformatics 28: 1647-1649.

Kirk, P.M. and Ansell, A. E. 1992. Authors of fungal names. Kew: CAB International.

Moustafa, A. F. and Abdel-Azeem, A.M. 2005. The genus Chaetomium in Egypt. El-Minia Sci. Bull. 16: 235-256.

White, T., Bruns, T., Lee, S. and Taylor, J. 1990. Amplification and direct sequencing of fungal ribososmal RNA genes for phylogenetics, in PCR Protocols, eds M. Innis, D. Gelfand, J. Sninsky, and T. White (NewYork,NY: AcademicPress,Inc.), 315-322. 
